\title{
Low Birth Weight and Exposure to Violence in Iraq
}

\author{
Wasan Ismail Ibrahim ${ }^{1}$, Aliaa Makki Hassan ${ }^{2}$, Eman Adnan Al-Kaseer ${ }^{3}$ \\ ${ }^{1} \mathrm{MB}$ ChB, Department of Community and Family Medicine, College of Medicine, Baghdad University \\ ${ }^{2}$ M.B.,CH.B./ FICM-CM, Department of Community and Family Medicine, College of Medicine, Baghdad University \\ ${ }^{3}$ M.B.,Ch.B. FICM-FM, Department of Community and Family Medicine, College of Medicine, Baghdad University
}

\begin{abstract}
In Iraq, the prevalence of low birth weight (LBW) was 9\% in the 1980 increased to $23.8 \%$ in $1990^{1}$ and increased to $50 \%$ after $2003^{2}$. Recently, Darweesh et $\mathrm{al}^{3}$ suggested that exposure to violence is a determinant of LBW in Iraq in addition to gestational weight gain (GWG). This work was carried out to assess gestational weight gain during pregnancy in Baghdad, Iraq.
\end{abstract}

A total of 408 mothers recently delivered attending primary health care centers (phcc) for vaccinated of their children. Interview as well as review of the antenatal care file was done.

Out of the total, $18.1 \%$ delivered LBW babies. The GWG of those delivered LBW was $12.5 \pm 4.6 \mathrm{~kg}$ and those who delivered normal birth weight babies were $12.5 \pm 3.4 \mathrm{~kg}$. No significant differences in gestational weight gain between those who delivered LBW and those who delivered normal birth weight babies (Table 1). The observed rate $(18.1 \%)$ is similar to that reported recently in Baghdad ${ }^{3,4}$. This rate is higher than in the neighbor countries ${ }^{5,6}$. This finding reflects the high LBW in Iraq.

No significant difference in GWG in delivering LBW or normal birth weight babies was noticed, which is inconsistent with that in literatures ${ }^{7}$. The difference might be explained of exposure to violence. Several articles showed that exposure to violence is a determinant to $\mathrm{LBW}^{8}$. Several articles in Iraq documented the exposure to widespread violence due to wars ${ }^{9,10}$. domestic violence is so common in Iraq ${ }^{11}$, which is in turns a new exposure to violence might be a determinant to LBW.

Exposure to violence might be contributed to LBW.

\section{References}

[1] Abdul Latif B, Al-Diwan JK, Al-Hadithi T, Al-Hadi A. Low birth weight and prematurity in neonatal unit in a maternity and paediatrics hospital in Iraq. J Trop Peditr 2006; 52: 148-150

[2] Al-Diwan JK, Al-Ageeli ST, Al-Hadfi A, Al-Hadithi T. Low birth weight in Baghdad, Iraq. J Fac Med Bagh 2006; 48: 363-365.

[3] Darweesh AM, Eman AL-Kaseer. Low Birth Weight in Post-Conflict Baghdad, Iraq. IJSR 2 4.438. Volume 4 Issue 6,e 2015. I J SR 2015; 4:

[4] AbdalQader M, Shah SA, Isa ZM, Ghazi HF, Badilla I, Hasan N. Factors related to low birth weight babies in Baghdad city, Iraq. M J P H M 2014; 14: 45-49
[5] 5- Mohammad K, Kassab M, Gamble J, Creedy DK, Foster J. Factors associated with birth weight inequalities in Jordan. Int Nurs Rev. 2014 Sep;61(3):435-40. Doi: 10.1111/inr.12120

[6] 6-Khademloo M, Karami H, Yasari M. Mothers prepregnancy body mass index, weight alterations and neonatal birth weight. Int J Med Invest 2015; vol 4; num 3;318-323

[7] 7- McDonald SD, Han Z, Mulla S, Lutsiv O, Lee T, Beyene J. High gestational weight gain and the risk of preterm birth and low birth weight: a systemic review and meta-analysis. J Obstet Gynaecol Can 2011;33(12):1223-1233

[8] 8- Asling- Monemi K, Pena r, Ellsberg MC, Person LA. Violence against women increases the risk of infant and child mortality: a care- referent study in Nicaragua. Bull WHO 2003; 81:1018

[9] 9- Burnham G, Lafta R, Doou S, Robert L. Mortality after 2003 invasion of Iraq: a cross- sectional cluster sample survey. http://www.thelancet.com . Published online Oct 11.2006.

[10]10- Iraqi Family Health Service Survey Group. Violence related mortality in Iraq from 2002 to 2006. N Engl J Med 2008; 358: 484- 493.

[11]11- Hashim RA. Physical intimate partner violence among women in Baghdad, Al Karkh 2014. Thesis, college of Meicine, Baghdad university. 2014

Table 1: Distribution of LBW with GWG

\begin{tabular}{|l|l|l|}
\hline Birth Weight & NO. & GWG \\
\hline LBW & 33 & $12.5 \pm 4.6$ \\
\hline NBW & 375 & $12.5 \pm 3.4$ \\
\hline
\end{tabular}

$\mathrm{t}=0.03, \mathrm{~d} . \mathrm{f}=406, \mathrm{p}=0.9$ 